https://helda.helsinki.fi

\title{
A cross-linguistic perspective on grammar and negative epistemics in talk-in-interaction
}

\section{Lindström, Jan Krister}

2016-12-01

Lindström , J K , Yael , M \& Pekarek Doehler , S 2016 , ' A cross-linguistic perspective on grammar and negative epistemics in talk-in-interaction ' , Journal of Pragmatics , no. 106 , pp. 72-79 . https://doi.org/10.1016/j.pragma.2016.09.003

http://hdl.handle.net/10138/172908

https://doi.org/10.1016/j.pragma.2016.09.003

unspecified

draft

Downloaded from Helda, University of Helsinki institutional repository.

This is an electronic reprint of the original article.

This reprint may differ from the original in pagination and typographic detail.

Please cite the original version. 


\title{
A cross-linguistic perspective on grammar and negative epistemics in talk-in-interaction
}

\author{
Jan Lindström ${ }^{1}$, Yael Maschler ${ }^{1}$, Simona Pekarek Doehler ${ }^{1}$
}

\begin{abstract}
In this introduction to the special issue on 'Grammar and negative epistemics in talk-in-interaction' we discuss the current state of research on the use of negative mental verb constructions such as I don't know, I don't understand, I don't remember in social interaction. We scrutinize, in a cross-linguistic perspective, the grammatical and interactional features that emerge from existing research in the field, and spell out the specific contribution of the studies collected in this issue. We discuss how the cumulative evidence provided by these studies across a set of different languages, several of which are typologically unrelated, contributes to studies of talk-in-interaction and to the newly emerging field of Pragmatic Typology. We argue that the findings point to universal interactional motivations for the grammatical properties and the grammaticization of the constructions studied, and suggest that these motivations arise out of the basic requirements for intersubjectivity in social interaction.
\end{abstract}

(C) 2016 Elsevier B.V. All rights reserved.

Keywords: Grammar-in-interaction; Talk-in-interaction; Epistemics; Negative mental verb constructions; Grammaticization; Pragmatic typology

\section{Aims and scope}

This special issue brings together empirical studies that explore the interrelatedness of grammar and social interaction within the realm of participants' displaying and negotiating states of 'no knowledge/understanding/remembering' in the course of social interaction. The focus is on how participants to social interaction use and orient to negative mental verb constructions such as I don't know, I don't understand, I don't remember across different languages. The key issue lies in the fact that participants may employ such constructions for a range of practical purposes that cannot be reduced to the disclaiming of epistemic access. There is then a side to such disclaimers in social interaction that may go far beyond issues of epistemic rights and access.

The contributors to the special issue share an understanding of grammar as thoroughly temporal, contingent and bound up with the moment-to-moment deployment of talk-in-interaction (see Auer, 2009; Hopper, 2011; Pekarek Doehler et al., 2015). They study grammar within the local ecology of talk, based on naturally occurring interactions, and paying close attention to how grammar is organically tied to turn and sequence organization. The special issue as a whole is designed to foster our understanding of grammar and grammaticization from a usage-based perspective, i.e., in light of its use in talk-in-interaction (see, e.g., Thompson et al., 2015), while contributing to the current debate on epistemics in interaction (see, e.g., Stivers et al., 2011; Heritage, 2012).

The originality of the present collection lies in its focus on first person negative epistemic expressions, and in bringing together evidence from a set of different languages, several of which are unrelated typologically. Existing studies of constructions involving mental verbs such as know have mostly focused on the 2nd person singular present tense positive form you know and its equivalents in other languages (e.g., Östman, 1981; Schourup, 1985; Schiffrin, 1987;

\footnotetext{
${ }^{1}$ These authors have contributed equally to this article.
} 
Macaulay, 2002 for English; Said-Mohand, 2007, for Spanish; Keevallik, 2003, for Estonian; Lindström and Wide, 2005, for Swedish; Maschler, 2012, for Hebrew). By contrast, first-person negative expressions of the type I don't know have been explored to a lesser extent (but see Beach and Metzger, 1997; Tsui, 1991; Scheibman, 2000; Weatherall, 2011, for English; Keevallik, 2003, 2011, for Estonian; Maschler, 2012, in press; Maschler and Dori-Hacohen, forthcoming, for Hebrew). Also, despite the current debate on epistemics in interaction, negative epistemic claims have been largely neglected in favor of the study of positive claims of knowledge (e.g. Heritage, 1984, 2012; Heritage and Raymond, 2005; Raymond and Heritage, 2006; Stivers et al., 2011; but see, again, Beach and Metzger, 1997; Hutchby, 2002; Mondada, 2011; Keevallik, 2011). By focusing on first person negative epistemic expressions across a variety of languages, then, the present collection fills a gap in research on grammar-in-interaction. The cumulative evidence provided by the studies presented here also contributes to the newly emerging field of Pragmatic Typology, investigating "the typology of systems of language use and the principles that shape them" (Dingemanse et al., 2014:5).

In what follows, we scrutinize, in a cross-linguistic perspective, the grammatical (section 2) and interactional (section 3 ) features that emerge from the current state of research on negative epistemic expressions, including research presented in this special issue, and address implications for our understanding of the interactional motivations for grammar (section 4).

\section{Grammatical features}

\subsection{Negative mental verb constructions across languages}

The articles in this special issue investigate subject-predicate constructions composed of a 1st person singular present tense negated form of an epistemic verb in seven languages: Estonian, Finnish, French, German, Hebrew, Mandarin Chinese, and Swedish, representing, thus, the Germanic and Romance branches of the Indo-European language family, the Finno-Ugric branch of the Uralic language family, the Semitic branch of the Afro-Asiatic language family, and the Chinese branch of the Sino-Tibetan language family. Semantically, the actual verbs investigated here express mental activities that have been considered to relate to universal core concepts (see Fortescue, 2001): know, understand, remember and forget. The verb 'to know' is perhaps the most common of these, and the one addressed by the majority of the studies in this collection (Helasvuo and Laury; Helmer et al.; Keevallik; Lindström and Karlsson; Pekarek Doehler). ${ }^{2}$ In its literal use, it communicates a speaker's state of access to some piece of knowledge, or in the negated form, lack of such access. 'Understanding' (investigated in Polak-Yitzhaki and Maschler), which is more dynamic than static 'knowing', brings the speaker's confrontation with a specific phenomenon and its meaning to the forefront, i.e. a process of sense-making and attaining, or not attaining, a new item of knowledge. 'Remembering' (investigated in Helasvuo and Laury; Tao) and 'forgetting' (Tao) have to do with making public the ability or inability to access or keep in mind some prior knowledge or experience.

However, it is important to note that by using such verbs in the 1st person singular, speakers merely report on their mental states (cf. Potter, 1996; Hutchby, 2002): They claim mental states rather than demonstrate them (cf. Sacks, 1992). Furthermore, as documented in several studies in this special issue, by means of such claims, speakers may get a range of interactional work done other than displaying lack of knowledge, understanding, or remembering. Also, the semantics of the epistemic verb are often considerably bleached when the negative epistemic construction is employed in interaction. The construction may then communicate other kinds of meaning, and its lexical semantics may be reduced to such an extent that the construction operates in a manner akin to a discourse marker (for 'I don't know' see Maschler, 2012, in press; Helmer et al.; Keevallik; Pekarek Doehler; Laury and Helasvuo, for 'I don't understand' see Polak-Yitzhaki and Maschler, for 'I don't remember' see Laury and Helasvuo). Such uses do not replace the literal uses of the constructions but rather live side by side with them. In this special issue, we are interested in the specific interactional jobs participants accomplish by means of such constructions, in the morphophonological and syntactic forms the constructions take, in the possible grammaticization paths they undergo, in how all these are interrelated, and how they compare across languages.

\subsection{Complement taking predicate constructions vs. formulaic fragments}

Syntactically, and according to traditional grammar, the verbs in our collection are all considered transitive verbs, each one taking two arguments - one for the experiencer of the cognitive state expressed by the verb, the other for the entity experienced, i.e. the matter known/understood/remembered/forgotten. Still according to traditional grammar, this latter argument is expressed either by an NP or by a subordinate object complement clause. However, there has been much work in a variety of languages, mainly following up on the seminal studies by Thompson and Mulac (1991) and Thompson (2002), showing that once examined in spontaneous discourse, this view of complementation can be problematic with regard to a

\footnotetext{
${ }^{2}$ When no year follows author, the reference is to an article in this special issue. Such references are separated by semicolons.
} 
variety of constructions and across a wide range of languages involving what has traditionally been considered complement-taking-predicates (e.g., Aijmer, 1996; Scheibman, 2000; Brinton, 2001; Kärkkäinen, 2003, 2007; Keevallik, 2003, 2006, 2011; Englebretson, 2003; Lindström and Wide, 2005; Laury, 2006; Imo, 2005, 2011; Hopper and Thompson, 2008; Endo, 2010, 2013; Deppermann, 2011; Laury and Okamoto, 2011; Pekarek Doehler, 2011; Maschler, 2012, in press; Helasvuo, 2014; Maschler and Nir, 2014; Posio, 2014). There is a strong tendency for the 'main' verbs of these constructions to be either verba dicendi, as in I said, she said, or mental verbs, in which the complement-taking-predicate (CTP)-phrase has an epistemic/evidential/evaluative meaning, with an overwhelming skewing towards epistemic meaning (Thompson, 2002:137). Nor are these structures necessarily bi-clausal constructions involving subordination. These CTPphrases are more adequately described as clause-external epistemic/evidential/evaluative formulaic fragments expressing speaker stance towards upcoming discourse. Rather than having matrix clause status, they function as projecting constructions (Auer, 2005; Günthner, 2006, 2011; Hopper and Thompson, 2008; Pekarek Doehler, 2011, 2015) - 'prefabs' that foreshadow certain types of action or turn-trajectories to come, which occupy a syntactically independent stretch of discourse often much longer than a clause. Quite often these CTP-phrases are morphophonologically reduced, and they frequently appear with no object complement whatsoever. Furthermore, these fragments often grammaticize (Hopper, 1987) into prototypical discourse markers (Maschler, 2009, 2012, in press; Pekarek Doehler, 2011, 2015). Thus, what traditionally would be analyzed as constructions requiring object complementation has often grammaticized into discoursemarkerhood, blurring the boundaries between syntactic subordination and structures involving no subordination at all.

\subsection{Syntactic and (morpho)phonological reduction}

One of the pervasive features across the typologically distinct languages studied here is that negative epistemic constructions in the 1st person present tense manifest morphophonological and/or syntactic reduction (see, e.g., Bybee, 2010, on such reduction as part of grammaticization). Estonian m(in)a+ei+tea 'I NEG know' ('I don't know') becomes maitea, mitea or even mtea; and the construction is often employed with no object complement (Keevallik). Similarly, Finnish mä en tiedä 'I NEG know' and en mä tiedä 'NEG I know' (for example, emmä tiä) show a tendency towards phonological reduction and no complementation, but there is also some variation in phonological realization which is connected to the syntactic form of the disclaimer (Laury and Helasvuo). French je ne sais pas ('I don't know') becomes je $n$ 'sais pas, je sais pas, $j$ 'sais pas, chais pas, and even ch'pas, and the reduced tokens tend to occur without object complement and to lose their meaning as a knowledge disclaimer (Pekarek Doehler). In German, the syntactically reduced forms of ich weiss nicht 'I don't know' (without complement) tend to function as pragmatic markers, while the syntactically 'fuller' forms (with complement) tend to function as full-fledged disclaimers of knowledge (Helmer et al.). Hebrew $\square$ ani lo mevin 'I not understand.sG.M' and $\square$ ani lo mevina 'I not understand.sG.F' ('I don't understand') become $\square$ an'lo mevin, $\square$ an'lo mvin, lo mvin for masculine forms, and $\square$ an'lo mevina, $\square$ an'lo mvina, lo mvina for feminine forms; the great majority of non-literal uses are morphophonologically reduced, and the construction may appear without an object complement (Polak-Yitzhaki and Maschler), although by far less frequently than Hebrew 'I don't know' (Maschler, in press). This is clearly a reflection of the fact that these Hebrew know tokens are much more frequent in the database and have therefore undergone grammaticization to a far greater extent than tokens of Hebrew understand, a point made also for Finnish 'I don't know' vs. 'I don't remember' (Laury and Helasvuo). While Tao does not address reduction for the Mandarin constructions, his data do show Mandarin 'I don't remember' and 'I forget' employed with no object complements. Similarly, the Swedish data in Lindström and Karlsson's study also manifest syntactic reduction of Swedish ja vet inte 'I don't know', which is used as a turn preface.

These findings across all the languages studied in our collection resonate with Scheibman's (2000) study on English, which demonstrates that the more pragmatic uses are typically accomplished by means of the morphophonologically reduced variant dunno while the more literal uses as epistemic disclaimer tend to be fulfilled by means of the fuller variant $I$ don't know. These observed tendencies to morphophonological and syntactic reduction support the claim that, across languages, negative epistemic verb constructions in the 1st person present tense are prone to be crystallized into fixed constructions, often discourse-marker-like, projecting certain types of actions to come and bearing specific interactional meanings. We now turn to a discussion of the precise interactional workings of the constructions at hand.

\section{Interactional features}

\subsection{Disclaimers of epistemic access}

Previous research on the interactional functions of epistemic disclaimers have focused on the expression I don't know, probably because this is one of the most common markers of epistemic stance in English (Kärkkäinen, 2003), which has been the language primarily focused on in research. Most studies of I don't know and its formal equivalents in other languages (henceforth generally called IDK) have examined the use in responsive turns, typically in responses to 
questions (Beach and Metzger, 1997; Drew, 1992), which is considered to be the most frequent sequential environment of its occurrence (Tsui, 1991). This is confirmed in this special issue by the studies on German (Helmer et al.), French (Pekarek Doehler), and Swedish (Lindström and Karlsson).

In such second position turns, IDK can constitute a stand-alone reply and be used in a literal sense, i.e. displaying the speaker's lack of knowledge about an issue at hand and thus his/her inability to answer. In this case, IDK is a non-answer response, blocking the sequential flow of interaction (Stivers and Robinson, 2006), and it can be heard as a disaligning, non-cooperating move. However, by disclaiming knowledge the speaker can also avoid expressing straightforward resistance and unwillingness to answer (Keevallik, 2011). Indicative of the sequential breach introduced by IDK responses to questions, they often lead to pursuit of a relevant answer in a follow-up question-answer sequence. Extract (1) from a child counseling session, quoted and discussed in Hutchby (2002), illustrates these sequential and social issues. The child $(P)$ avoids collaborating in counseling talk by persistently using stand-alone don't know responses while the counselor (C) endeavors to produce therapeutically relevant talk (see also Stickle, 2015, for I don't know used by children with autism in response to evaluation questions).

(1) From Hutchby, 2002:156.

62 C: Why d'you think, (1.8) mum an' dad said what they said.

$63(0.4)$

64 P: Don't know,

$65(4.1)$

$66 \mathrm{C}:$ Cuz it sounds like they were a bit cross.

$67(0.6)$

68 P: Don't know,

$69 \mathrm{C}$ : Who d'you think they're cross with.=

$70 \mathrm{P}:=$ Don't $\mathrm{kno}[\mathrm{w}$,

71 C: [.h O:h I think you do:[:, I think you're playing]=

72 P: 73 C: $=$ [games with me.

74 P: $[$. hhh hih=hih

Such examples then show that speakers may use knowledge disclaimers to get a range of interactional purposes accomplished that go far beyond the mere display of lack of knowledge. References to lack of knowledge can indicate the speaker's resisting the trajectory of the action initiated, for example, heading off sensitive topics (Tsui, 1991; Hutchby, 2002; Weatherall, 2011; Maschler, 2012, in press), like a difficult family-related issue in extract (1). Such steering away from a topic has also been attested in this special issue by Helmer at al.'s study on German. Furthermore, stand-alone IDK responses may imply that the interactional problem lies with the question (rather than the response), which is thus treated as illegitimate, improper or inappropriate (Keevallik, 2011; Maschler and Dori-Hacohen, forthcoming; see also Mondada, 2011). Also, such uncooperative interactive behavior may be socially risky, which is probably why many IDK responses are elaborated by an account for the speaker's insufficient knowledge or an attempt to provide some kind of compensating information which might be helpful in the context (Beach and Metzger, 1997; Stivers and Robinson, 2006; Keevallik, 2011; Maschler, 2012; Maschler and Dori-Hacohen, forthcoming; Pekarek Doehler).

\subsection{Markers of (epistemic) stance}

The constructions discussed in this special issue are recurrently deployed in interaction with a bleached literal meaning, in which case they often function to convey epistemic stance. For instance, the negative epistemic marker IDK makes a prefatory move which signifies the speaker's stance to what is said in a fuller continued response turn (cf. Schegloff, 1996:62). Several studies have reported a variety of interactional functions for such prefatory uses of epistemic disclaimers, the common denominator of which is some sort of epistemic downgrading of the content of the speaker's subsequent contribution. For example, IDK can preface a hunch or a guess (Beach and Metzger, 1997:569; Maschler, 2012; Pekarek Doehler):

(2) From Beach and Metzger, 1997:569.

S: Wonder how he found out an all that, $(0.4)$

F: I: : : I don't know through work or Kay probably, 
This bleached literal meaning found in disclaimers of a cognitive state is common also to Hebrew 'I don't understand', such that the great majority of tokens in casual conversation data are employed as fixed chunks conveying puzzled stance, often disaffiliative. Most often this chunk is used to convey critical stance towards the addressee and/or a non-present referent (Polak-Yitzhaki and Maschler). This is reminiscent of the German construction ich verstehe nicht which can be employed in order to convey reproach (Deppermann, 2011). Thus, rather than epistemic stance, what is conveyed by the 'I don't understand' construction seems to be affective stance.

This bleached literal meaning of a cognitive state is common also to Finnish and Mandarin 'I don't remember' and to Mandarin 'I forget'. Laury and Helasvuo illustrate uses of Finnish 'I don't remember' followed by utterances indicating that the speaker does in fact remember the issue at hand. It has been shown that English claims of forgetfulness can serve as a resource for altering the participation framework in various ways, for example by encouraging participation and cotellership by a co-participant (Goodwin, 1987). Laury and Helasvuo's study points in this direction with the observation that Finnish 'I don't remember' tokens tend to occur in sequences where collective remembering is taking place, serving as a participatory resource. However, claims of not remembering may also be used to avoid accountability and display resistance, as shown by Muntigl and Choi (2010) in a study of couples' therapy sessions. In a similar vein, Tao analyzes Mandarin 'I don't remember' and 'I forget' in conversational episodes where disputed memory becomes the issue, i.e. when speakers contradict each other in the recollection of past events or experiences. Such disputes may have various personal and interpersonal motivations, including selective remembering by the same speaker.

In addition to seeking information, questions may express requests and invitations, and thus may receive responses containing IDK by which the speaker avoids making a commitment (since an IDK response neither complies nor declines; Beach and Metzger, 1997; Tsui, 1991), and may by the same token also reject the preceding inviting move (Keevallik, 2011). The latter is confirmed here by Lindström and Karlsson's study on Swedish, showing that IDK occurs frequently in responses which are non-conforming to type-specifying questions (cf. Heritage and Raymond, 2005) and hence displays speaker's resistance to something about the question. Related observations are presented in Helmer et al.'s study on German and Pekarek Doehler's investigation on French.

The construction also occurs in first position turns, where it can be understood to work towards downgrading the epistemic certainty of a description, as shown by Weatherall (2011) in a study of I don't know as "a prepositioned epistemic hedge". Such hedges are found in first assessments containing complaints or criticisms (or even self-deprecations) that can be problematic somehow, for example, through exaggeration (see Weatherall, 2011). In these contexts the disclaimer signals that the speaker is not fully committed to the possibly provocative or otherwise inaccurate content of the upcoming turn, and that this content should not be taken as literal or certain. Therefore, IDK prefaces also serve as alerts of an approximation, for example, before inexact descriptions of past events, including information about times or prices-a function also addressed by Pekarek Doehler (see also Maschler, 2012). In related research, Potter (1996) has shown how I don't know tagged on to the end of a turn "inoculates" the speaker against possible negative inferences.

\subsection{Uses as an interaction-organizing device}

The observations outlined above suggest that references to a negative epistemic stance clearly reflect the socially normative preference organization in interaction according to which speakers should cooperate, i.e. confirm rather than disconfirm, agree rather than disagree, comply rather than decline, accept rather than reject (Pomerantz, 1984). Here we turn to uses of the construction IDK as an interaction-organizing device with only minimal (if any) residual epistemicity. Several studies in this issue document that the non-literal uses of IDK in talk-in-interaction cannot be reduced to the function of marking epistemic stance or hedging, but are instrumental in how participants sequentially organize the interaction and how they make this organization mutually recognizable. In this type of use, IDK signals an upcoming dispreferred response in which the speaker cannot meet the conditions of social preference (see also Keevallik, 2011; Maschler, in press; Maschler and Dori-Hacohen, forthcoming). In this special issue, the question of preference is addressed by Helmer et al., who identify uses of IDK in German that project a dispreferred response, by Pekarek Doehler, who documents IDK in French as a resource for projecting a non-fitted response, and by Lindström and Karlsson, who relate the analysis to participants' asymmetrical knowledge domains in Swedish medical interaction. All of these are turninitial or near-to turn-initial uses that serve the purpose of projecting some departure from the normatively expected next action.

Additionally, Pekarek Doehler shows how, in turn-final position in responses to questions, IDK serves as a turn-exit device at a moment when such exit is not warranted by conditional relevance, i.e. at a moment when the normatively expected next action has not (yet) been accomplished and the turn-so-far remains pragmatically incomplete. Also, the negative epistemic marker may be employed to close down talk on topics which might lead to disagreement (Beach and Metzger, 1997; Tsui, 1991; Maschler, in press; Maschler and Dori-Hacohen, forthcoming). This functional property is also identified by Maschler (in press), Helmer et al., and Keevallik, who show that formal equivalents of I don't know in Hebrew, German, and Estonian, respectively, can be used for the purpose of steering away from a topic. 
The constructions, in all of the cited uses, are most often highly grammaticized (see section 2.3) and function much like discourse-markers in serving as interaction-organizing resources.

\section{The cumulative evidence: some steps towards a Pragmatic Typology}

The studies collected in this special issue on negative epistemics open new perspectives on a field of investigation that has, with a few notable exceptions, only recently attracted the attention of research on grammar and social interaction. First, by exploring a range of languages, the studies considerably broaden the empirical basis for our understanding of the display and negotiation of states of 'no knowledge/understanding/remembering' in the course of social interaction. Second, the studies further our understanding of the grammatical constructions involved: the findings reported here show strong convergences, across languages, as to how complement taking predicate phrases of the I don't know, I don't understand or I don't remember type undergo morphophonological and syntactic reduction and often grammaticize into discourse markers. Third, the studies document, across several languages and a variety of social settings, the various ways speakers put to use these constructions in order to accomplish some practical interactional business, ranging from literal uses, to stance-related matters (usually epistemic stance, but sometimes affective stance), and finally to organizational uses related, e.g., to the projection of a dispreferred next action or to exiting a topic, a turn, or a sequence.

In sum, this special issue breaks new ground by demonstrating that negative epistemic verb constructions in the 1st person singular present tense are prone to be crystallized into fixed constructions projecting certain types of actions to come and bearing specific interactional functions. The convergences between the grammatical features, the sequential positioning and the interactional functions documented in this collection across several languages have important consequences for our understanding of grammar and its relation to social interaction. The cumulative evidence emanating from the studies in this special issue points to universal interactional motivations for the grammatical properties and grammaticization of the constructions studied, and it suggests that these pertain to the basic requirements for intersubjectivity, in the sense of participants' mutual coordination and understanding of the social actions accomplished in talk-in-interaction.

\section{Acknowledgements}

We are grateful to Sandy Thompson and Cecilia Ford for their insightful comments on an earlier version of this paper.

\section{References}

Aijmer, Karin, 1996. I think - an English modal particle. In: Swan, Toril, Westvik, Olaf Jansen (Eds.), Modality in Germanic Languages. Mouton de Gruyter, Berlin, pp. 1-47.

Auer, Peter, 2005. Projection in interaction and projection in grammar. Text 25, 7-36.

Auer, Peter, 2009. On-line syntax: thoughts on the temporality of spoken language. Lang. Sci. 31, 1-13.

Beach, Wayne A., Metzger, Terri R., 1997. Claiming insufficient knowledge. Hum. Commun. Res. 23, 562-588.

Brinton, Laurel J., 2001. From matrix clause to pragmatic marker: the history of look-forms. J. Hist. Pragmat. 2, 177-199.

Bybee Joan, 2010. Language, Usage and Cognition. Cambridge UP, Cambridge.

Deppermann, Arnulf, 2011. Constructions vs. lexical items as sources of complex meanings. A comparative study of constructions with German verstehen. In: Auer, Peter, Pfänder, Stefan (Eds.), Constructions: Emerging and Emergent. Mouton de Gruyter, Berlin, pp. 88-126.

Dingemanse, Mark, Blythe, Joe, Dirksmeyer, Tyko, 2014. Formats for other-initiation of repair across languages: an exercise in pragmatic typology. Stud. Lang. 38 (1), 5-43.

Drew, Paul, 1992. Contested evidence in courtroom cross-examination: the case of a trial for rape. In: Drew, Paul, Heritage, John (Eds.), Talk at Work. Cambridge University Press, Cambridge, pp. 470-520.

Endo, Tomoko, 2010. Epistemic stance marker as a disagreement preface: wo juede 'I feel/think' in Mandarin conversation in response to assessments. Kyoto Univ. Linguist. Res. 29, 43-76.

Endo, Tomoko, 2013. Epistemic stance in Mandarin conversation: the positions and functions of wo juede "I think. In: Pan, Yuling, Kádár, Daniel (Eds.), Chinese Discourse and Interaction: Theory and Practice. Equinox, London, pp. 12-34.

Englebretson, Robert, 2003. Searching for Structure: The Problem of Complementation in Colloquial Indonesian Conversation. Benjamins, Amsterdam/Philadelphia.

Fortescue, Michael, 2001. Thoughts about thought. Cognit. Linguist. 12 (1), 15-45.

Goodwin, Charles, 1987. Forgetfulness as an interactive resource. Soc. Psychol. Q. 50 (2), 115-131.

Günthner, Susanne, 2006. "Was inn trieb, war vor allem Wanderlust" (Hesse: Narziss und Goldmund): Pseudocleft-Konstruktionen im Deutschen. In: Günthner, Susanne, Imo, Wolfgang (Eds.), Konstruktionen in der Interaktion. Mouton de Gruyter, Berlin/New York, pp. 59-90.

Günthner, Susanne, 2011. Between emergence and sedimentation: projecting constructions in German interactions. In: Auer, Peter, Pfänder, Stefan (Eds.), Constructions: Emerging and Emergent. Walter de Gruyter, Berlin, pp. 156-185.

Helasvuo, Marja-Liisa, 2014. Agreement or crystallization: patterns of 1st and 2 nd person subjects and verbs of cognition in Finnish conversational interaction. J. Pragmat. 63, 63-78. 
Heritage, John, 1984. A change of state token and aspects of its sequential placement. In: Maxwell Atkinson, J., Heritage, John (Eds.), Structures of Social Action. Cambridge University Press, Cambridge, pp. 299-345.

Heritage, John, 2012. The epistemic engine: sequence organization and territories of knowledge. Res. Lang. Soc. Interact. 45 (1), $30-52$.

Heritage, John, Raymond, Geoffrey, 2005. The terms of agreement: indexing epistemic authority and subordination in assessment sequences. Soc. Psychol. Q. 68, 15-38.

Hopper, Paul J., 1987. Emergent grammar. Berkeley Linguist. Soc. 13, 139-157.

Hopper, Paul J., 2011. Emergent grammar and temporality in interactional linguistics. In: Auer, Peter, Pfänder, Stefan (Eds.), Constructions: Emerging and Emergent. Walter de Gruyter, Berlin, pp. 22-44.

Hopper, Paul J., Thompson, Sandra A., 2008. Projectability and clause combining in interaction. In: Laury, Ritva (Ed.), Crosslinguistic Studies of Clause Combining. John Benjamins, Amsterdam, pp. 99-123.

Hutchby, lan, 2002. Resisting the incitement to talk in child counselling: aspects of the utterance "I don't know". Discourse Stud. 4 (2), $147-168$. Imo, Wolfgang, 2005. A Construction Grammar approach to the phrase "I mean" in spoken English. InLiSt (Interact. Linguist. Struct.) 42.

Imo, Wolfgang, 2011. Clines of subordination - constructions with the German 'complement-taking predicate' glauben. In: Laury, Ritva, Suzuki, Ryoko (Eds.), Subordination in Conversation: A Cross-linguistic Perspective. John Benjamins, Amsterdam, pp. 165-190.

Kärkkäinen, Elise, 2003. Epistemic Stance in English Conversation: A Description of Interactional Functions, With a Focus on / Think. John Benjamins, Amsterdam/Philadelphia.

Kärkkäinen, Elise, 2007. The role of I guess in conversational stancetaking. In: Englebretson, Robert (Ed.), Stancetaking in Discourse: Subjectivity, Evaluation, Interaction. John Benjamins, Amsterdam, pp. 183-219.

Keevallik, Leelo, 2003. From interaction to grammar: Estonian finite verb forms in conversation (Diss., University of Uppsala). Acta Universitatis Upsaliensis, Studia Uralica Upsaliensia 34.

Keevallik, Leelo, 2006. From discourse pattern to epistemic marker: Estonian (ei) tea 'don't know'. Nordic J. Linguist. 29, 173-200.

Keevallik, Leelo, 2011. The terms of not knowing. In: Stivers, Tanya, Mondada, Lorenza, Steensig, Jakob (Eds.), The Morality of Knowledge in Conversation. Cambridge University Press, Cambridge, pp. 184-206.

Laury, Ritva, 2006. On subordination, Finnish-style: questioning the category of finite clausal complements in spoken Finnish. SKY J. Linguist. Suppl. 19, 310-321.

Laury, Ritva, Okamoto, Shigeko, 2011. Teyuka and I mean as pragmatic parentheticals in Japanese and English. In: Laury, Ritva, Suzuki, Ryoko (Eds.), Subordination in Conversation: A Cross-linguistic Perspective. John Benjamins, Amsterdam, pp. 209-238.

Lindström, Jan, Wide, Camilla, 2005. Tracing the origins of a set of discourse particles: Swedish particles of the type you know. J. Hist. Pragmat. 6 , 211-236.

Macaulay, Ronald, 2002. You know, it depends. J. Pragmat. 34, 749-767.

Maschler, Yael, 2009. Metalanguage in Interaction: Hebrew Discourse Markers. John Benjamins, Amsterdam/Philadelphia.

Maschler, Yael, 2012. Emergent projecting constructions: the case of Hebrew yada ('know'). Stud. Lang. 36 (4), $785-847$.

Maschler, Yael, 2016. The emergence of Hebrew loydea/loydat ('I dunno masc/fem') from interaction: blurring the boundaries between discourse marker, pragmatic marker, and modal particle. In: Sansò, Andrea, Fedriani, Chiara (Eds.), Pragmatic Markers, Discourse Markers and Modal Particles: New Perspectives. John Benjamins, Amsterdam/Philadelphia (in press).

Maschler, Yael, Dori-Hacohen, Gonen, 2016. Hebrew lo yode'a/lo yoda'at '(I) don't know' on Israeli political radio phone-ins. (forthcoming).

Maschler, Yael, Nir, Bracha, 2014. Complementation in linear and dialogic syntax: the case of Hebrew divergently aligned discourse. Cognit. Linguist. 25 (3), 523-557.

Mondada, Lorenza, 2011. The management of knowledge discrepancies and of epistemic changes in institutional interactions. In: Stivers, Tanya, Mondada, Lorenza, Steensig, Jabob (Eds.), The Morality of Knowledge in Conversation. Cambridge University Press, Cambridge, pp. $27-57$.

Muntigl, Peter, Choi, Kwok Tim, 2010. Not remembering as a practical epistemic resource in couples therapy. Discourse Stud. 12 (3), $331-356$.

Östman, Jan-Ola, 1981. "You Know": A Discourse Functional View. John Benjamins, Amsterdam.

Pekarek Doehler, Simona, 2011. Clause-combining and the sequencing of actions: projector constructions in French talk-in-interaction. In: Laury, Ritva, Suzuki, Ryoko (Eds.), Subordination in Conversation: A Cross-linguistic Perspective. John Benjamins, Amsterdam, pp. 103-148.

Pekarek Doehler, Simona, 2015. Grammar, projection and turn-organization: (il) y a NP 'there is NP' as a projector construction in French talk-ininteraction. In: Deppermann, Arnulf, Günthner, Susanne (Eds.), Temporality in Interaction. John Benjamins, Amsterdam/Philadelphia, pp. 173-199.

Pekarek Doehler, Simona, De Stefani, Elwys, Horlacher, Anne-Sylvie, 2015. Time and Emergence in Grammar. John Benjamins, Amsterdam/ Philadelphia.

Pomerantz, A., 1984. Agreeing and disagreeing with assessments: some features of preferred/dispreferred turn shapes. In: Atkinson, J.M., Heritage, J. (Eds.), Structures of Social Action. Cambridge University Press, Cambridge, pp. 57-111.

Posio, Pekka, 2014. Subject expression in grammaticalizing constructions: the case of creo and acho 'I think' in Spanish and Portuguese. J. Pragmat. 63, 5-18.

Potter, Jonathan, 1996. Representing Reality. Sage, London.

Raymond, Geoffrey, Heritage, John, 2006. The epistemics of social relations: owning grandchildren. Lang. Soc. 35 (5), $677-706$.

Sacks, Harvey, 1992. Lectures on Conversation, vol. 2. Blackwell, Oxford.

Said-Mohand, Aixa, 2007. A sociolinguistic approach to the discourse marker tu sabes 'you know' in the speech of young US bilinguals. Southwest J. Linguist. 26, 67-93.

Schegloff, Emanuel, 1996. Turn organization: one intersection of grammar and interaction. In: Ochs, Elinor, Schegloff, Emanuel, Thompson, Sandra (Eds.), Interaction and Grammar. Cambridge University Press, Cambridge, pp. 52-133.

Scheibman, Joanne, 2000. I dunno: a usage-based account of the phonological reduction of don't in American English conversation. J. Pragmat. 32, 105-124.

Schiffrin, Deborah, 1987. Discourse Markers. Cambridge University Press, Cambridge.

Schourup, Lawrence C., 1985. Common discourse particles in English conversation (Diss., Columbus: Ohio State University, 1983). Garland, New York. 
Stickle, Trini, 2015. Epistemic stance markers and the function of I don't know in the talk of persons with dementia and children with autism (Diss. University of Wisconsin-Madison). ProQuest, Ann Arbor.

Stivers, Tanya, Robinson, Jeffrey D., 2006. A preference for progressivity in interaction. Lang. Soc. 35 (3), 367-392.

Stivers, Tanya, Mondada, Lorenza, Steensig, Jakob (Eds.), 2011. The Morality of Knowledge in Conversation. Cambridge University Press, Cambridge.

Thompson, Sandra A., 2002. "Object complements" and conversation: towards a realistic account. Stud. Lang. 26, $125-163$.

Thompson, Sandra A., Mulac, Anthony, 1991. A quantitative perspective on the grammaticization of epistemic parentheticals in English. In: Traugott, Elizabeth Closs, Heine, Bernd (Eds.), Approaches to Grammaticalization, vol. II. John Benjamins, Amsterdam, pp. 313-329.

Thompson, Sandra A., Fox, Barbara A., Couper-Kuhlen, Elizabeth, 2015. Grammar in Everyday Talk: Building Responsive Actions. Cambridge University Press, Cambridge.

Tsui, Amy B.M., 1991. The pragmatic functions of I don't know. Text 11, 607-622.

Weatherall, Ann, 2011. I don't know as a prepositioned epistemic hedge. Res. Lang. Soc. Interact. 44 (4), 317-337. 